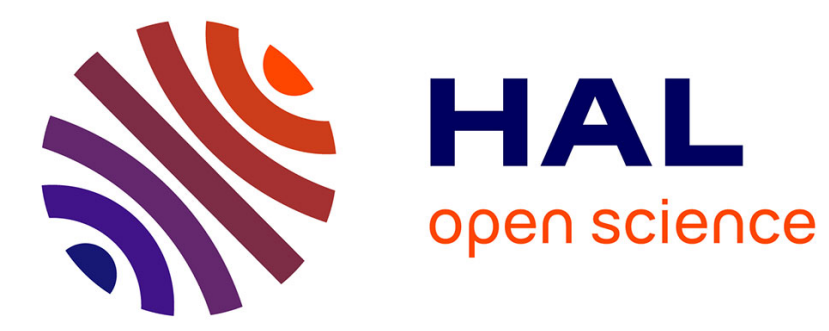

\title{
An evolutionary theory of urban systems
}

Denise Pumain

\section{To cite this version:}

Denise Pumain. An evolutionary theory of urban systems. Rozenblat C., Pumain D., Velasquez E. International and Transnational Perspectives on Urban Systems., Springer, 2018, ISBN: 978-981-107798-2. 10.1007/978-981-10-7799-9_1 . hal-03118244

\section{HAL Id: hal-03118244 \\ https://hal.science/hal-03118244}

Submitted on 22 Jan 2021

HAL is a multi-disciplinary open access archive for the deposit and dissemination of scientific research documents, whether they are published or not. The documents may come from teaching and research institutions in France or abroad, or from public or private research centers.
L'archive ouverte pluridisciplinaire HAL, est destinée au dépôt et à la diffusion de documents scientifiques de niveau recherche, publiés ou non, émanant des établissements d'enseignement et de recherche français ou étrangers, des laboratoires publics ou privés. 


\section{Denise Pumain: An evolutionary theory of urban systems}

in Rozenblat C. Pumain D. Velasquez E. 2018, International and Transnational Perspectives on Urban Systems. Springer Nature, Advances in Geographical and Environmental Sciences, 3-18. (ISBN: 978-981-10-7798-2)

The urban evolution seems to be beyond any global political or economic control that the recently revealed scarcity in energy and resources renders necessary. Therefore, a theory providing a better understanding of urban dynamics and processes could help to draw future scenarios. Since our theory stipulates that evolution of cities is mainly driven by their specific relative situation, in terms of location, size and functions, within systems of cities, the challenge is to identify how the key principles of urban dynamic and interaction processes are operating and to assess whether there is a chance for changing them using urban governance at different levels.

In this study, we attempt to theorize why cities of the same country or region in the world maintain such huge differences in size, which may range from possibly a few thousands to tens of millions of residents. We also try to explain why they keep for long periods of time the same relative rankings in these regional urban hierarchies and how and why urban growth is shifting between different "generations" of cities and between different regions of the world.

The theory developed in this book encompasses as far as possible the existing state of knowledge in urban sciences for identifying regularities at the world scale and enabling worldwide comparisons. Some of the major dimensions that we develop below in a non-trivial way include considering the theory as comprehensively geographical and rooted in complex systems of science and evolution. Our urban theory is constructed according to nomothetic principles, but it avoids any naturalism or determinism; it belongs definitely to the domain of social sciences. As such, it tries to develop a meaningful interpretation of the common "universal" features of urban dynamics without forgetting to include the major elements of urban diversity that were generated over centuries by different geographical conditions and historical geopolitical trajectories.

\section{A geographical theory}

Many scholars currently debate urban theory and the "nature" of cities. We share the opinion that "the crucial task [is] of demarcating the inner logic of urbanization from other social processes" (Scott and Storper, 2014, p. 4). We agree with the authors that common features can be identified in the evolution of urban systems and that "there are systematic regularities in urban life that are susceptible to high levels of theoretical generalization" (ibid. p. 12). However, we think it necessary to avoid two pitfalls in urban definitions, which would be overestimating the present urban functionalities and reducing the interpretation to a single or too narrow a disciplinary field. Compared to a dominant interpretation of urban systems that relies mainly on principles of economic geography and urban economy and because our interest 
is in envisaging urban systems in their global diversity, we focus on dynamic processes generating an open evolution through history, and we try to consider the societal complexity of factors that are involved in the variety of urban structures.

Although the participants in this book belong to a variety of academic disciplines, the regularities that we want to explain with our theory are mainly the major geographical features of urban systems. Because we pay attention to theoretical building on a global scale and over historical time, "geographical" means including three key elements in our theoretical construction: geographical space is conceived, not as a topographic or administrative-political bounded container but as a relational space whose properties emerge from a variety of societal interactions; urban entities are conceived at two distinct scales of analysis, i.e., cities and systems of cities, in a way that keep a meaningful definition over centuries and across civilizations; our explanation for the regularities that are included in the theory is not based on any "universal law" or "optimal solution" to urban processes, neither are they considered as tending toward any equilibrium or as representing a more or less desirable societal norm: Instead, our theory explains these regularities from a generic open urban dynamic operating on the long run and the deviations from the derived statistical models are made interpretable by including in the theory the major testable factors of this urban "geo-diversity".

\subsection{Geography as spatial interaction}

The dramatic proliferation of exchanges of all kinds, including goods, people and information at all geographical scales, using increasingly sophisticated technical inventions, may lead us to think that entering a "network society" (Castells, 1996) is a recent phenomenon. However, this is far from new. For instance, the title taken for this section is an expression employed by the American geographer Edward Ullman in a paper dated 1954. Moreover, we know from archaeological and historical literature that the emergence of cities as a new kind of sociospatial entities (i.e., compared to previous forms of nomadic habitat or agricultural villages) is linked with the establishment of relatively long distance connections (Bairoch, 1985; Markus, Sabloff, 2008). Political analysts have long recognized the fundamental relational and competitive character of urban entities, as did Giovanni Botero in a remarkable explanation "Delle Cause della Grandezza et Magnificenza della Città" included in his book about "La Ragion di Stato" (Botero, 1588, see Pumain, Gaudin, 2002).

In the long history of human societies, if viewed in a social engineer's naïve viewpoint as an expression of our "collective intelligence", cities and systems of cities could appear as an extremely sustainable invention, a multi-scale adaptive tool for managing resources and for controlling territories and networks. In brief, cities differ from villages by escaping from a strong local constraint threatening their development because of the limited resources and uncertainties of their immediate environment (i.e., their site) through the exploitation of more distant resources that they capture or create from interactions with more distant sites (i.e., shifting the constraint from their site towards a dependence upon their constructed geographical situation). Networking enables cities to escape the limitations of local resources and, at the same time, requires emulation to continue innovation in the rivalry and competition with other cities. Although initially relying on their geopolitical power and their technical ability in conducting wars (Turchin, 2003; Turchin et al., 2013) as well as on the capacity of their regional 
agriculture to accumulate a surplus and sustain an embryonic division of labor, the development of cities and systems of cities is increasingly rooted in the innovation process both stemming from local and distant interactions, which constrains them to continue to change in order to have the chance to survive and later maintain the economic and symbolic value of their urban assets. This function of urban systems as a societal adapter is multiple and operates at different scales in space and in time. It is not by accident that the same word, "city" has been kept for millennia for designing a way of inhabiting the planet, which may include a variety of regional forms and changes in morphological appearance and societal content over time.

The presence of cities still introduces a morphological distinction with the countryside because of a much higher density of buildings and infrastructures. Their generally growing dynamics is the opposite of the countryside where land use is dedicated to agriculture and demographic trends generally oriented to decline. However, over time, the sharp sociological and cultural differences that were associated with the population residing in cities and the countryside (i.e., often marked by different political status for the inhabitants) have been blurred, and the "urban way of life" has been widely disseminated all over the planet, especially through new communication technologies. Differences remain, however, more perceptible in the parts of the world that are still less urbanized. However, compared to the initial stage of rapid urban development during the $19^{\text {th }}$ century in industrialized countries where urban immigrants were submitted to high mortality levels, the sanitary conditions have improved to the extent that currently, healthcare is now of a higher standard in urban areas than in the countryside in less developed countries.

\subsection{Cities as systems within systems of cities}

Observing cities through time and across a diversity of countries requires an understanding that enables an abstract view of the functions they fulfill. Classically, at least since Brian Berry coined the expression of "cities as systems of cities" in 1964, (and as already mentioned by the French Saint-Simonian engineer Jean Reynaud in 1841, [see Robic, 1982]), geographers identify two forms in relational space that exhibit different properties and correspond to two distinct spatio-temporal scales of interactions.

Because they create fields of spatial attractiveness and concentration, "cities" are privileged interaction spaces where people, households, firms and a series of collective institutions interact and organize their daily lives. As each of these urban "individual citizens" has to connect on average three or four different places of activity each day, they usually dedicate one hour of time to commuting (i.e., that regularity is often referred to as "Zahavi's law"). It means that there is a constraint on the spatial expansion of cities, which cannot exceed a radius of four to five kilometers when people were moving by walking. However, now, with space-time contraction thanks to the acceleration of motor transportation, we can reach some thirty or forty kilometers or more within the same one hour of time. We use this spatio-temporal envelope of roughly one hour for defining cities in a comparable way over time and making cross-country comparisons, including the diversity of local statistical definitions (Bretagnolle et al., 2002). At that level, the one hour constraint is enough to understand that under the growing demand for accessibility to the center of cities, a sharp gradient of urban prices and an increase in densities are generated between the center and its periphery, while according to a variety of social and 
urbanism rules, different mosaics of activity zones and segregation patterns among residents of different income and origins may be observed.

At the upper geographical scale, systems of cities are sets of highly connected cities whose interactions have generated strong interdependencies in their demographic and functional evolution. Such systems are not easy to delineate, especially because the scope of interurban interactions is wider when cities are larger. One day travel for connecting activities in another city within a system of cities would be roughly the critical time for defining such systems. Although the interactions at that scale are less frequent on average for individual citizens and firms, those requiring face-to-face transactions are using travel as a means whose speed has increased much more rapidly than those ensuring intra-urban movements: the speed was multiplied by a factor of approximately forty for the past two hundred years, whereas inside cities, it has increased only by a factor of approximately five. In space-time, when linkages are measured according to travelling time, the intra-urban space now appears as relatively dilated compared to the more constricted inter-urban space. From these weaker but high speed interactions, systems of cities have developed universal structural properties, including a strong hierarchical differentiation of city sizes and an inter-urban division of labor, inducing a diversity of functional specializations and more or less regular spatial patterns.

An urban theory that would try to explain "the" city alone is thus necessarily incomplete. Since their emergence in Mesopotamia, and then in an independent way in three or four other regions of the world (e.g., Indus valley, South China, Central America, and tropical Africa...) cities have always been connected with others in systems of cities. For many centuries, the major constraint upon their development remained, however, in the natural and political conditions within their close environment, including natural hazards and local inter-urban rivalries. From the time of the opening of maritime trade on a global scale and later with the first industrial revolution, the developmental constraint seemed to be less embedded in local resources and stemmed mainly from competition with other cities, while urban networks started covering the planet. Currently, the ecological constraint has become again perceptible when envisaging the future of cities, but the resilient urban solutions will no longer depend on the local environment only. The systems of cities will be the channel through which the international regulations relative to energy and climate will percolate top-down towards every city, while local initiatives for ensuring a reduced consumption of natural resources will be disseminated bottom up from "creative cities" through the system of cities.

\subsection{A geo-historical interpretation of urban diversity}

Spatially, urbanization can be understood only if the networks conveying exchanges are multiple, diversified and frequent. It is because goods, persons and information circulate that all over the planet cities are growing and adapting to the societal, technological, economic and cultural changes that they continuously generate and have increasingly become the reference for organizing the life of societies in geographical space. Because of the interconnectedness that ensures the interdependence in their evolution, the dynamics of systems of cities are spatially universal; nevertheless, they exhibit multiple specificities linked with their history, the timing of their development and the interactions with their particular environment. 
The emergence of cities as self-organized systems of cities occurred through processes that can be observed at two main levels, i.e., local and long distance interactions, which have often been simultaneous and combined in their effects. The more general emergence proceeds from interactions between local villages, where food storage and agriculture have accumulated a surplus and multiplied the population densities by a factor of 100 compared to previous huntergatherer communities. Only a small part of the population could live without spending all their time on subsistence, and the speciation of new personal skills developed a division of labor. Political, religious, craft and market functions concentrated in towns, which progressively hierarchized in networks of central places (Christaller, 1933) through the diversification of their activities (Marcus and Sabloff, 2008). The multifold domination of the urban centers over their complementary agricultural settlements ensured the sustainability of these early urban systems, while individual cities benefitted for their development from resources that they shared or extracted from other cities. In parallel, political territories and "civilizations" developed from these cities, and sustaining them was built up through the multiple institutions representing societal order and behavioral norms. This was the major process of emergence of systems of cities in history within territorial (i.e., geopolitical) "niches" mainly between the Neolithic and Medieval times.

However, a second process sustained the development of more specialized cities organized in networks through long distance connections. That second process is sometimes created mainly through trade, but more often, it is linked to the formation of very large and more or less sustainable empires, as observed in various regions of the world. For example, some of the wellknown examples at different periods are the cities of the silk road between Asia and Europe, Phoenician trading posts (i.e., from the $12^{\text {th }}$ century BC, as Tyr, Cyprus, Crete, Sicily, Malta, Cadiz, and Carthage), Venetian trading posts and colonies (i.e., the $13^{\text {th }}-15^{\text {th }}$ centuries) on the Mediterranean shores, cities of the Hanseatic League (i.e., the $12^{\text {th }}-17^{\text {th }}$ centuries) along the Baltic Sea, cities of triangular colonial trade (i.e., the $16^{\text {th }}-19^{\text {th }}$ centuries) on both sides of the Atlantic Ocean, ports of the maritime roads on the Pacific Ocean (the $20^{\text {th }}$ century), and even today, the nodes of global financial markets (i.e., whose physical connections do matter) illustrate that mode of organization forming chained networks of cities (e.g., New York, Tokyo, and London). After a while, all urban regions in the world became connected by more or less regular exchanges through which the local urban systems were developing mutual influences and complementarities. The lowering of transportation cost associated with the Industrial Revolution and the accompanying immense progress in productivity triggered huge population migrations towards urban centers starting around the end of $18^{\text {th }}$ century, and the "urban transition" has come to an end in the more developed countries but is still operating in the emerging and poor economies.

Both processes of emergence and further consolidation of systems of cities, either mainly based on local interactions or on long distance trade, were observed, and their traces co-exist in all regions of the world. That is why very general principles of urban dynamics have been identified from their comparison, and we will see below how they hold together in a consistent evolutionary theory of urban systems. Due to the path dependence dynamics in complex systems, cities keep specific identities in terms of their landscapes, morphological, social and 
cultural aspects, the urban conditions of living are not equalized nor standardized, although they share many similar constraints in their organization and transformation.

Moreover, although generic processes have had rather similar consequences on the spatial organization and demographic evolution of cities, the delays that were observed over history in urban settlement and development lead to broadly recognize three distinct types of systems of cities at world scale. The regions where the urbanization process was rather continuous include Asia and Europe because they have higher densities of small towns and less concentrated distributions of city sizes. At the opposite end of the spectrum, regions where urban settlements were imported later, i.e., the "New World", including North America and Australia, have lower densities in their systems of cities and sharper contrasts in their size distribution. The less developed countries that entered much later (i.e., mostly around 1950) in the urban transition and were before for decades submitted to colonization very often have a mixed (i.e., "dual") pattern of cities, including more or less regular networks of central places having emerged from local interactions and large "oversized" metropolis, which were implemented for international trade by the colonial power (Moriconi-Ebrard, 1993). Thus, the geopolitical history of the different world regions left traces in the geographical organization of systems of cities, which adds a more systematic source of geo-diversity to the many other urban cultural, linguistic, societal and morphological local peculiarities.

\section{A complex systems theory}

Why refer to complex systems about cities? Our intention is neither to be fashionable nor to import concepts and models from "harder" sciences to artificially inject robustness in our epistemological construction. Indeed, if we refer to this framework, it is because the observations that were made repeatedly on the processes of urban change (Pumain, Saint-Julien, 1978; Pumain, 1982; Pumain et al., 1989; Lane et al., 2009) exhibited similarities with processes that were analyzed in other disciplinary fields addressing self-organization then complexity theories (Prigogine, Stengers, 1973; Haken, 1977; Arthur, 1994; Allen, 1997). We were able to successfully transfer these concepts and models to the analysis of urban systems and to integrate some of their powerful derived analytic tools to our statistical investigation and computer simulation of urban dynamics (Pumain, Sanders, 2013). We briefly recall below the main results that were meaningfully integrated in our theory of urban systems (Pumain, 1997).

\subsection{Explanation of emerging urban properties from socio-spatial interactions}

There is a paradox that we want to explain regarding the persistency of the rankings of cities within urban hierarchies over rather long periods of time, i.e., many decades or centuries (Fig.1). The hierarchy of cities is maintained despite the multiple perturbations occurring in their environments, including major economic changes and political events, which result in high fluctuations of the growth trends for individual cities, and despite the apparently Brownian movement of people and firms, appearing and disappearing, in and out-migrating within cities over much shorter time scales. The concept of "order through fluctuations" enunciated in theories of self-organized complex systems (Prigogine, Stengers, 1973) illustrates this paradoxical evolution. The distribution of city sizes can be interpreted as a universal property of the systems of cities that emerge from their mutual interactions. 
Figure 1: Cities co-evolution in urban hierarchies

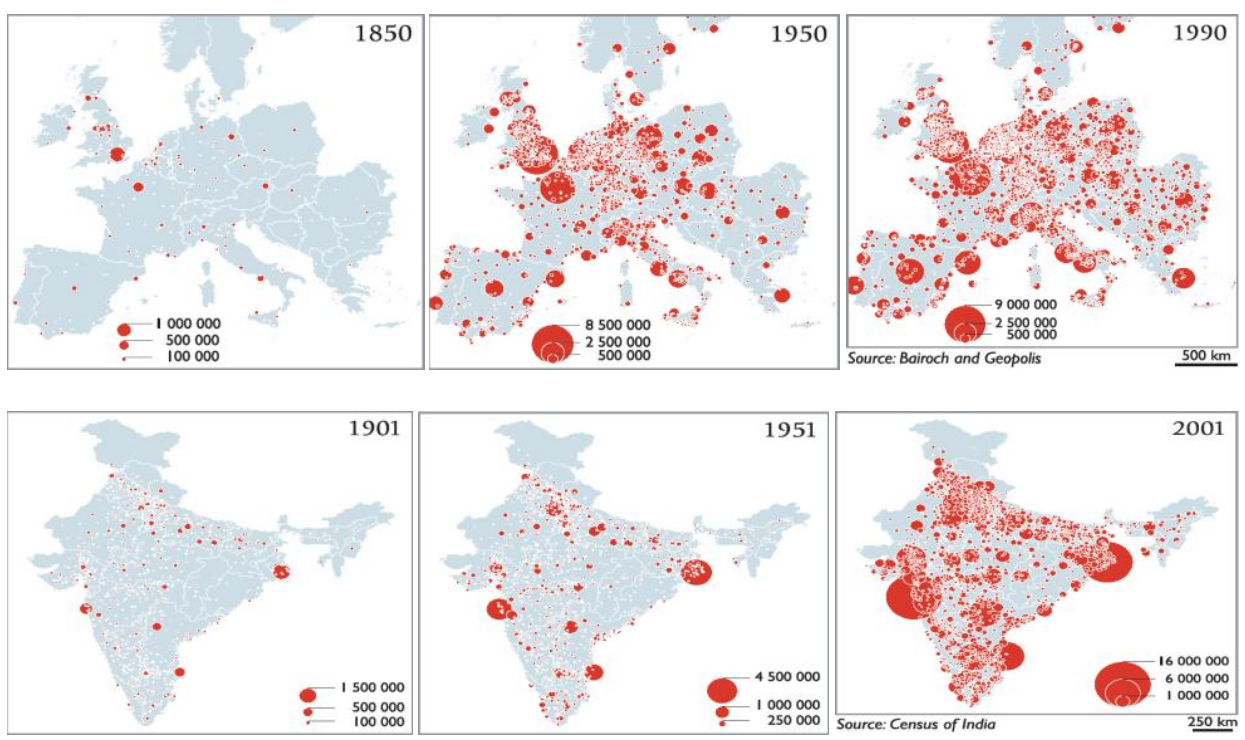

Source : Bretagnolle et al. (2007)

First, why do we observe everywhere such a regular form of the statistical distribution of city sizes? This so-named "rank-size rule" by George Kinsgley Zipf (1941), "one of the most overwhelming empirical regularities in economics" (Fig.2) and still an "empirical mystery", according to Paul Krugman (1996), received an interesting explanation as early as 1931 by the French statistician Robert Gibrat. He demonstrated that a lognormal distribution of city sizes (i.e., partly similar to Zipf's "rank size rule") can be generated by a simple statistical process of random growth where all cities have about the same average growth rate with a variance, ensuring small fluctuations that are independent of size and past growth. The search for explanation is thus shifted to understanding the existence of a high similarity of growth rates in a system of connected cities, but it would be paradoxical to accept that it results from a stochastic process implying they are independent! Many empirical studies (on England and Wales: Robson, 1973, France: Pumain, 1982, China and India: Swerts, 2013) have confirmed that on long enough historical periods and in well-connected systems of cities, the observed growth process is rather well approximated by this simple model, but a slight trend for higher growth rates in larger cities and some periods of temporal auto-correlation due to interurban interactions should be added to the purely random statistical process (Favaro, Pumain, 2011, Pumain et al., 2015). This explanation including interactions can be introduced in simulation models (as the Simpop models, Pumain, 2012) where cities are not independent of each other, as in the purely statistical model. The interaction processes are implemented according to the way urban innovation disseminates in the system of cities that we detail below (Bura et al., 1996, Sanders, 1987, Bretagnolle, Pumain, 2010, Cottineau, 2014).

Indeed, it is because the stakeholders in cities are continuously interacting with stakeholders in other cities that all types of urban changes are rapidly disseminated through the system of cities in quantitative as well as in qualitative terms: in the long run the cities belonging to the same system of cities evolve around a common growth rate and their activities, skills of their labor 
force and even cultural practices are transformed in more or less the same way. This process of spatial diffusion of urban innovations was noticed long ago by the geographer T. Hägerstrand (1952). Hägerstrand coined the diffusion process as mainly constrained by the effect of distance, as summarized in the "mean information field" according to a gravity model around the centers. When the diffusion process describes entrepreneurial activities it also becomes "hierarchical", meaning that the largest cities in each system are able to capture most of the innovations in their early stage, at the moment where they provide not only higher risk but also higher benefits, because of the comparative advantage of large cities in terms of availability of capital, skilled employment and market opportunities (Fig.3). This has been confirmed by many empirical observations of historical processes of innovation diffusion in systems of cities (Robson, 1973; Pred, 1973 and 1977; Lepetit, 1988). The process of interurban innovation diffusion is by no means a passive percolation process because it results from a proactive action of urban stakeholders for capturing the benefit of any kind of novelty that may appear at any time in the system.

Figure 2: Rank-size distributions in a selection of countries (including BRICS) in 2010

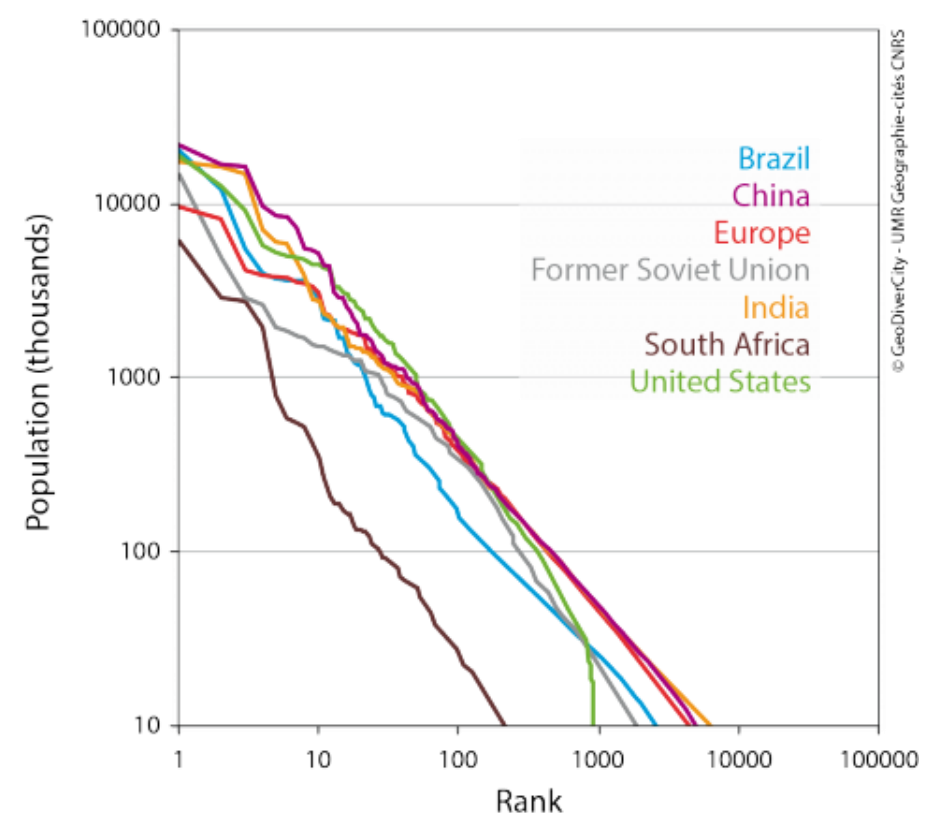

Source: Pumain et al. (2015)

Interurban interaction also explains the remarkable sustainability of urban systems. The sustainability is all the more remarkable because of its mostly self-organized character. Even at the city level and moreover at the scale of systems of cities, urban systems were not frequently conceived as "institutions", i.e., organizations having clearly defined objectives that would result from a social convention designed for that purpose, although in the course of history, there were a few single cities, or even city networks, which were for a while founded as such by political or religious powers, colonizers or developers. However, the resilience of urban networks is indeed very large: the medieval historians have established that a century after the disaster of the Great Plague, which halved the size of the population in Europe circa 1350, the cities had recovered not only their previous population but also the rank they held in the 
European urban hierarchy a century ago. Even at that early time in urban history, relations between the towns were sufficiently numerous and regular that the recovery of each operates in synergy with the others, and the external disturbance represented by the catastrophe disrupted the path of each city without substantially altering the intrinsic organization of the system of cities, which results from its competitive dynamics.

Figure 3: Schematic hierarchical diffusion of innovation cycles in systems of cities

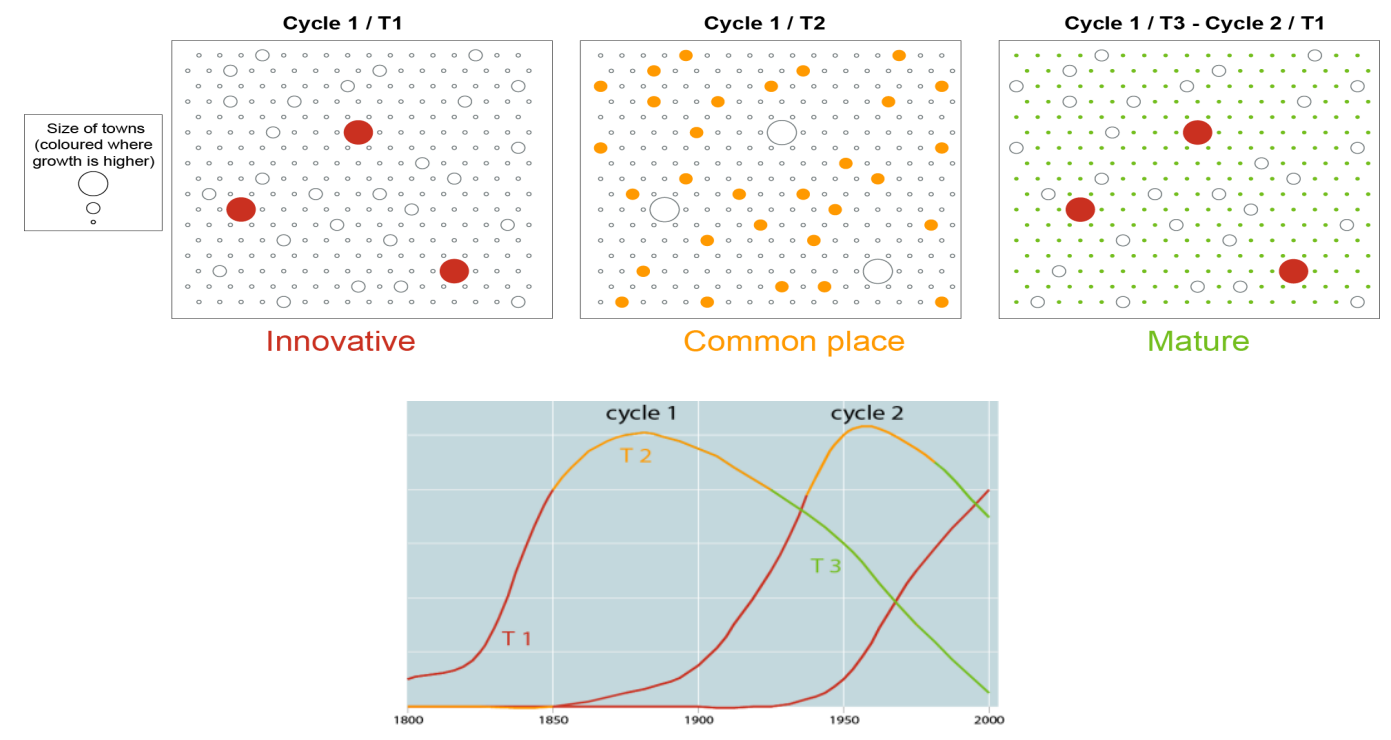

Source: Pumain et al. (2009)

\subsection{Nonlinear behavior, stable trajectories and bifurcations}

The evolution of urban hierarchies, however, is not a simple homothetic translation of the system of cities towards a state of larger size, higher wealth and a more complex economy and society. We already noticed that the hierarchical character of the inter-urban diffusion of innovation induces a slight trend towards higher (i.e., or at least more stable) growth rates for the largest cities of the system. The same process combined with the contraction of relational space over time due to the increasing speed of communications induces in the long run a trend toward a slower growth of the smallest cities that are short-circuited by the expansion of the sphere of influence of large metropolises. This results in a "simplification from below" of urban hierarchies, where the smallest units progressively lose their relative central functions. Empirical observation of the evolution of urban systems confirms that in the long run the inequalities in city sizes are increased and urban hierarchies are reinforced (Pumain et al., 2015). This trend is captured with the mathematics of allometric relationships between urban population and the amount of their attributes, which is also called "scaling laws" that summarize the trend of innovative activities to concentrate relatively in larger cities at the beginning of each new innovation wave, despite offering higher costs for wages and rents, while mature activities remain or are relocated in smaller towns at the declining stage of the wave (Pumain et al., 2006, Bettencourt, Samaniego and Youn, 2014).

There is another important source of nonlinearity in the evolution of urban systems that is created by the recurrent process of specialization of a rather small number of cities, which 
concentrate a high proportion of an activity specific to an innovation wave, usually because the city is located near to or within a zone of resources, such as a coal basin or an oil field; when the city is close to some touristic amenity; the origin of location also may be a concentration of skills and research investment (i.e., as with route 128 or the Silicon Valley in the US, or Bangalore in India for electronic activities); or a regional societal organization favoring the adoption of innovation (i.e., as in relatively small towns of "Third Italy" in the second half of the twentieth century). Geographers first recognized this phenomenon as creating "generations of cities" specialized, for instance, in textile or steel manufacturing industries. It has generated a huge body of literature, and regional science and geographical economy also aim to explain modeling and predicting where such "activity clusters" were or would be located and which are the determinants of their creation and survival.

At the macro-level of the system of cities, the process of specialization is part of the "division of labor" between cities. While the classical diffusion of innovation waves and their associated growth impulses create and increase the quantitative inequalities of sizes within a system of cities, the specialization process structures the major qualitative differences that are observed between cities in their employment profiles, professional composition, and average income levels. A classical pattern that was observed in comparing French or European cities as well as North American, Chinese and Indian ones by means of multivariate analysis establishes that the major dimension differentiating their societal characteristic today is the trace of the location of manufacturing activities of the first industrial revolution (i.e., including mainly mining, textile and steel industries), while the second dimension reflects the differential adaptation of cities to the "revolution of services" since the second half of $20^{\text {th }}$ century (i.e., opposing cities where finance, insurance and real estate activities and business services have had intense developments to cities where traditional small trade and craft remained relatively more present). Over time, during each large innovation wave, the specialization process creates cases of anomalous rapid growth for single cities or regional pockets of cities, which surge in higher ranks and may partly reshape the urban hierarchy. At the meso-level of single cities, the specialization by definition represents a large part of the economic base and, for a few decades at least, makes the city residents wealthy and increases the attractiveness of the city. Therefore, it generates peculiar non-smooth growth trajectories that remain ascending as long as the innovation wave is productive enough, but very often exhibit tipping points and reversal when the highly specialized cities fail to adapt to further innovation (Fig.4). Comparative analysis of the systems of cities of the BRICS, Europe and the United States of America provides many examples of these few but important "anomalous" trajectories that contrast with the generally smooth trend of growth in urban hierarchies (Pumain et al., 2015).

\section{Figure 4 : Tipping points in urban trajectories and urban specialization}



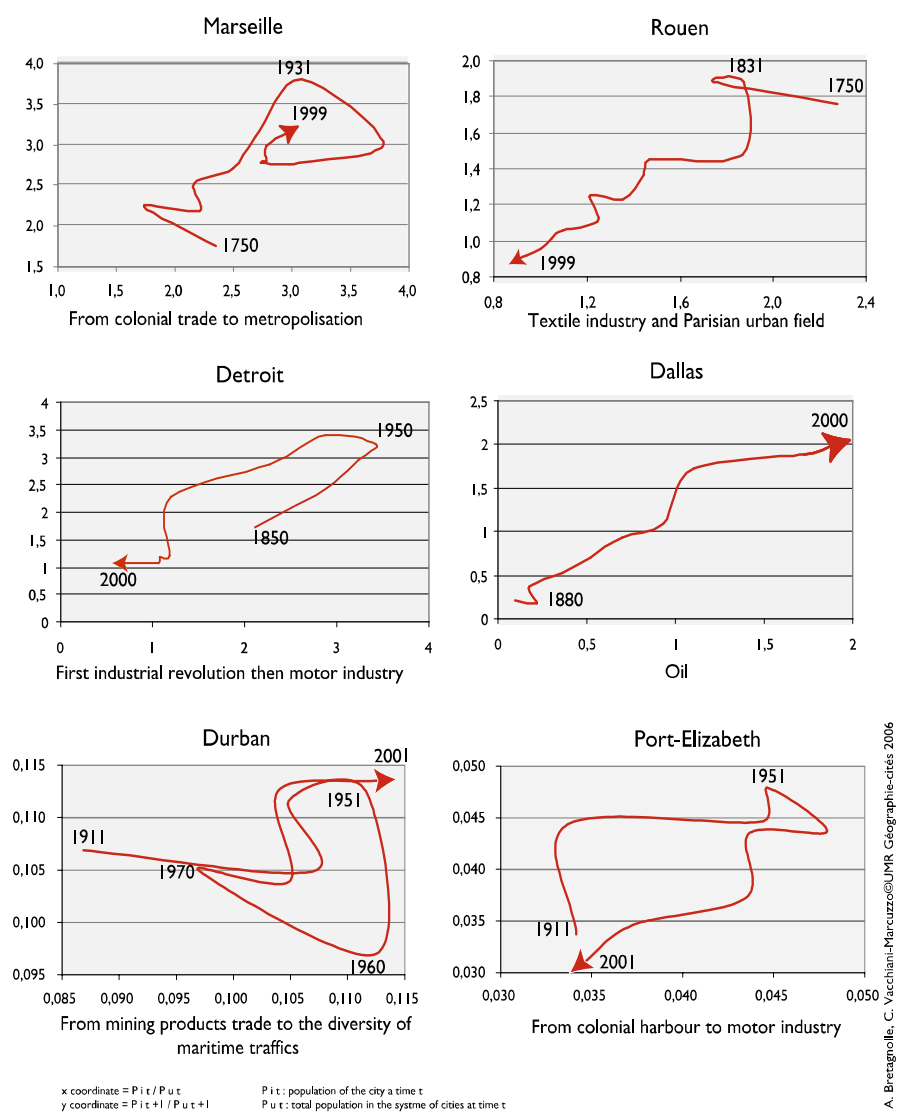

Legend: On x axis: population of a city at time t/population of the system of cities at time $t$; on $y$ axis: population of the city at time $t+1 /$ population of the city at time $t+1$

Source: Bretagnolle A., Pumain D., Vacchiani-Marcuzzo C., 2007, Les formes des systèmes de villes dans le monde, in Mattéi M.-F., Pumain D. (dir) : Données urbaines, 5, p. 313.

The more spectacular non linearity in evolution is observed at world scale because the new international division of labor linked to the lowering of transportation and transactional costs has shifted many activities of previous economic cycles towards the cities of less developed countries where wages were lower. Whereas the first globalization until $20^{\text {th }}$ century had had little incidence on the development of cities in colonized countries, because raw materials and agricultural products were the main goods for exchange at that time, there was a first rapid urban growth at first in the New World, when investments started to develop manufacturing in the United States after first world war, and overall a huge transfer or manufacturing activities after second world war - Chinese cities of the Eastern coast have then been for a few decades the manufacturing centers exporting products all over the world with extraordinary urban growth rates until the rise of salaries lead to shift some of their activities to the cities of other poorer Asiatic countries. Of course this major shift in urban specialization does not summarize all changes in urban activities that occurred because of economic and financial globalization and new exchange networks that we detail in chapter 2 . 


\section{Conclusion: an evolutionary theory}

The evolutionary theory of urban systems is conceived for providing an explanation of their general transformation through a generic dynamics and some specific path- dependent effects of historical events and geographical processes. It may appear surprising to develop a theory not relying at first on the current societal and economic forces that are referred to in the theoretical debates currently referred in geography, i.e. the overwhelming development of capitalism and the geopolitics of globalization. Of course we recognize as major driving forces the economic activity which provides the energy for developing and sustaining the cities as well as the political influence that shapes the destiny of territories within which cities self-organize in systems of cities all over the world. However if we search for a genuine explanation of urban evolution we find the concept of complex adaptive system through interaction a more general key for explanation. It is the only way to account for the broad similarities between old and more recent urban systems that have functioned for long independently on five continents under quite different political, economic and cultural norms. In this process indeed it is the urban diversity at all scales which appears as a major driving force of the evolution.

The theory also enables to overcome the apparent paradox of cities being intrinsic places of change whose hierarchies exhibit a remarkable persistency: observing the pervasive urbanization trends of the last century despite the important changes they have generated raises a major challenge for urban research. The theory underlines that there is no need for separate theories of "cities of the global south" or "post-colonial cities" because these cities nevertheless share some major generic properties of urban systems and can be interpreted better if not assuming a priori that they are 'specific'. The theory also allows deepening such comparisons and better specifying geographical peculiarities in measuring the deviations from a generic urban organization and dynamics.

Why are these systems adaptive? A too simple transfer of an explanation from individual psychology would claim for the rationality of imitation (Tarde) or the impulse of mimetic desire (Girard) in the urban adaptive process. Indeed, these rationales may be in action at the individual level of urban stakeholders who are engaged proactively in a process of maintaining and possibly increasing the value of their urban assets. The urban value is too rarely made measurable but has to be considered here in its multifold dimensions including not only the monetary term but also the symbolic, relational, cultural and patrimonial aspects of cities. This set of individual actions however have not additive but multiplicative effects because of the creativity of human social interactions which generate all kinds of innovation.

This view of urban systems as expressing such a collective territorial intelligence could be taken in consideration when facing the next challenges to which our societies will next be confronted: the ecological transition made necessary from climatic change and planetary resource limitation, the growing contrasts between still growing and shrinking cities after the urban transition has come to an end, and the geopolitical tensions generated at all levels, inside and between cities, by increasing inequalities in income distribution. 


\section{References}

Allen P., (1997). Cities an Regions as Self-organizing Systems: Models of Complexity. Amsterdam, Gordon and Breach.

Arthur W. B., (1994). Increasing returns and path dependance in the Economy, Ann Harbor, Michigan : University of Michigan Press.

Bairoch, P., (1985), De Jericho à Mexico, Gallimard, Paris.

Batty M. (2005). Cities and complexity. The MIT Press.

Berry B.J.L. (1964). Cities as systems within systems of cities. Papers of the Regional Science Association, 13, 147-163.

Bettencourt L., Samaniego H. \& Youn H., (2014). Professional diversity and the productivity of cities. Nature Scientific reports 4, 5393.

Botero G., (1588). Della cause della grandezza e magnificenza delle città. Tre libri. New edition in 1598 with the book "La Ragion di Stato" ( $7^{\text {th }}$ edition) in Venezia and a cura di Luigi Firpo by the Unione Tipografico Editrice Torinese in 1941.

Bourne L. Sinclair R. Dziewonski K. (eds) (1984). Urbanization and Settlement Systems: International Perspectives. Oxford, Oxford University Press.

Bretagnolle A. Paulus F. Pumain D. (2002). Time and space scales for measuring urban growth. Cybergeo, 219, $12 \mathrm{p}$.

Bretagnolle A., Pumain D., Vacchiani-Marcuzzo C., (2007). Les formes des systèmes de villes dans le monde, in Mattéi M.-F., Pumain D. (dir) : Données urbaines, 5, 301-314.

Bretagnolle A., Pumain D. (2010). Simulating urban networks through multiscalar space-time dynamics (Europe and United States, 17th -20th centuries), Urban Studies, 47, 13, 2819-2839.

Bura S. Guérin-Pace F. Mathian H. Pumain D. Sanders L. (1996). Multi-agent systems and the dynamics of a settlement system. Geographical Analysis, 2, 161-178.

Cottineau C. (2014). L'évolution des villes dans l'espace post-soviétique. Observation et modélisations. Université Paris I, PhD thesis.

Frankhauser P. (1994). La fractalité des structures urbaines. Economica, Paris.

Fujita, M., Krugman, P. and Mori, T., (1994). On the evolution of hierarchical urban systems, North American meeting of the Regional Science Association, Niagara Falls.

Fujita, M., Krugman, P., and Venables, A.J., (1999). The Spatial Economy, The MIT Press, Cambridge.

Gibrat R. (1931). Les inégalités économiques. Sirey, Paris.

Haken H. (1977). Synergetics, an Introduction: Nonequilibrium Phase Transitions and SelfOrganization in Physics, Chemistry, and Biology, Springer-Verlag.

Krugman P. (1996). Confronting the mystery of urban hierarchy. Journal of Japanese and International Economies, 10, 399-418.

Lane D., Pumain D., van der Leeuw S., West G. (eds.), (2009). Complexity perspectives on innovation and social change, ISCOM, Springer, Methodos Series 7, 492 p.

Lepetit B. (1988). Les villes dans la France moderne (1740-1840). Paris, Albin Michel. 
Marcus J. and Sabloff J. A. (eds) (2008). The Ancient City. New perspectives on Urbanism in the Old and New World. SAR Press, 405 p.

Martin R. (2008). Path Dependence and Path Creation in the Economic Landscape, in Boschma, R. and Martin, R. (Eds) Handbook of Evolutionary Economic Geography, Cheltenham: Edward Elgar.

Moriconi-Ebrard, F., (1993). L'urbanisation du monde depuis 1950, Anthropos, Paris.

Pred A., (1977). City systems in advanced economies, London, Hutchinson.

Prigogine I. Stengers I. (1973). La nouvelle alliance. Paris, Gallimard.

Pumain D. (1982). La dynamique des villes. Paris, Economica, 231 p.

Pumain D. (1997). Vers une théorie évolutive des villes. L'Espace Géographique, 2, 119-134.

Pumain, D., (2004). Scaling laws and urban systems. Santa Fe Institute, Working Paper $\mathrm{n}^{\circ} 04-$ 02-002, 26 p.

Pumain D., (ed) (2006). Hierarchy in natural and social sciences, Dordrecht, Kluwer.

Pumain D. (2012). Multi-agents System Modelling for Urban Systems : the Series of

SIMPOP models, in Heppenstall A. J., Crooks A.T., See L.M., Batty M. (eds), Agent-based

Models of Geographical Systems. Springer, Population Studies, 721-738.

Pumain D. Saint-Julien T., (1978). Les dimensions du changement urbain. Paris, CNRS, 202 p.

Pumain D., Saint-Julien T., Sanders L., (1989). Villes et auto-organisation. Paris, Economica, $191 \mathrm{p}$.

Pumain D. Gaudin J.-P. (2002). Systèmes de villes et pouvoir. L'analyse de Giovanni Botero à l'époque de la Renaissance. Cybergeo, 227, 19 p.

Pumain D., Swerts E., Cottineau C. Vacchiani-Marcuzzo C., Ignazzi A., Bretagnolle A., Delisle F., Cura R., Lizzi L, Baffi S. (2015). Multi-level comparison of large urban systems. Cybergeo, 706, http://cybergeo.revues.org/26730 ; DOI : 10.4000/cybergeo.26730.

Reynaud, J., (1841). Villes, in Encyclopédie nouvelle, Gosselin, Paris, vol. VIII, pp. 670-687 (discovered by Robic, 1982).

Robic, M.-C., (1982). Cent ans avant Christaller, une théorie des lieux centraux, L'Espace Géographique. 1 : 5-12.

Sanders L. Pumain D. Mathian H. Guérin-Pace F. Bura S. (1997). SIMPOP: a multi-agent system for the study of urbanism. Environment and Planning B, 24, 287-305

Scott A.J. Storper M. (2014). The Nature of Cities: the Scope and Limits of Urban Theory. International Journal of Urban and Regional Research, DOI 10.1111/1468-2427.12134.

Storper, M., Kemeny, T., Makarem, N., \& Osman, T. (2015). The Rise and Fall of Urban Economies: Lessons from San Francisco and Los Angeles. Stanford University Press.

Turchin, P. (2003). .Historical Dynamics: Why States Rise and Fall. Cambridge: Cambridge

University Press.

Turchin P. Currie T.R. Turner E.A.L. Gavrilets S. (2013). War, space and the evolution of Old world complex societies. PNAS, 110, 41, 16384-16389.

Ullman, E., (1954). Geography as spatial interaction, in Interregional linkages. The proceedings of the Western Committee on Regional Economic Analysis. Berkeley, California, 63-71,

Zipf, G.K., (1941). National unity and disunity, Principia Press, Bloomington (Indiana). 